\title{
Winter wheat productivity on southern micellar- carbonate chernozem depending on phosphorus supply
}

\author{
Anatolii Izotov ${ }^{1, *}$, Boris Tarasenko ${ }^{1}$, and Dmitrii Dudarev ${ }^{1}$ \\ ${ }^{1}$ V.I. Vernadsky Crimean Federal University, 4, prosp. Vernadskogo, 295492, Simferopol, Russia
}

\begin{abstract}
An analysis was made of the variability of the content of available phosphates in the layer of $0-20 \mathrm{~cm}$ of low humus southern micellar-carbonate chernozem and the features of their spatial distribution were estimated. Models of the dependence of the yield of winter wheat on the content of available phosphates in the soil and on the dose of mineral phosphorus fertilizers have been developed. The results can be used to calculate spatially differentiated doses of phosphorus fertilizers.
\end{abstract}

\section{Introduction}

Improving the efficiency of technology for growing winter wheat in southern Russia is one of the most important tasks of agronomic science and practice. It provides an increase in the production of safe and quality products while minimizing the unit costs of financial, energy and labor funds [1]. To solve this problem in the technology of growing winter wheat, it is necessary to ensure the rational use of zonal natural resources [2]. Among them, a special place is occupied by soil cover with its special agrochemical properties. One of the agrochemical factors that critically affect the yield of winter wheat is the availability of available forms of phosphates in the soil [3-5]. It should be noted that the natural reserves of compounds of available phosphorus in the southern chernozem are not always sufficient to fully satisfy the needs of wheat plants in this nutrient. In this case, phosphorus deficiency can be compensated by adding mineral phosphorus fertilizers while growing winter wheat [6-9]. It should be taken into account that steppe zone soils are characterized by a significant spatial heterogeneity in the supply of available phosphates, due to which small agrochemical contours are formed within the fields. This significantly complicates the achievement of the goal of rational use of phosphorus fertilizers in doses that provide the maximum economic return from yield increase [10-12]. One of the ways to solve this problem is to develop methods for calculating spatially differentiated doses of phosphorus fertilizers for use in accurate technologies for growing winter wheat.

However, on the southern carbonate chernozems in the conditions of the Crimean peninsula, the variability of available phosphates' content in the soil has not yet been adequately studied, a statistically significant quantitative dependence of the yield of winter wheat on both their content in the soil and increasing doses of phosphorus fertilizers has not been established.

*Corresponding author: a.m.izotov@mail.ru 


\section{Material and research methods}

Our research was conducted in the Crimean steppe zone in the conditions of the agricultural enterprise LLC "Rosa-Agro" of the Sovetskiy district. Within the field crop rotation on the southern micellar-carbonate low humus chernozem, two plots of sainfoin crops with a low content of available phosphates in the arable layer (from 7 to 10 and from 10 to $13 \mathrm{mg} / \mathrm{kg}$ of soil according to Machigin) were successively set aside. For each of them for three years (for a total of six years) a two-factor field experiment with winter wheat was laid according to the method of split-plots. On the main plots of experiment, organized with fourfold frequency according to the scheme of randomized repetitions, four levels of soil supply with available phosphates were formed in advance [13-15]. For this purpose, three doses of ammophos at the rate of 90, 200 and $450 \mathrm{~kg}$ of $\mathrm{P}_{2} \mathrm{O}_{5}$ per 1 ha together with the variant of absolute control were applied annually while plowing sainfoin at each repetition in accordance with the experimental design. The plot thus prepared was set aside for the background sowing of winter wheat - a precursor for the experiment. After harvesting the precursor in the main plots of the experiment, soil diagnostics of the available phosphates' content was carried out. Then, each of the main plots was split into four sub-plots with randomly located phosphorus fertilizer options: $0,30,60$, and $120 \mathrm{~kg} / \mathrm{ha} \mathrm{P}_{2} \mathrm{O}_{5}$. Fertilizers in the form of ammophos were applied for each plot under the main tillage. The harvested area of the sub-plot was $54 \mathrm{~m} 2$. Subsequently, winter wheat sowing and care was carried out in accordance with zonal recommendations.

In order to study the spatial heterogeneity of the distribution of the available phosphates' content in the soil, 254 test sites of $20 * 20 \mathrm{~m}$ in size, located along a regular orthogonal grid, were allocated on the additional site of 10.2 ha. Five point samples of soil layer $0 \ldots 20 \mathrm{~cm}$ were taken from each of them. To obtain the maximum representativeness of the samples, one of them was taken in the center of the square platform and four more on its diagonals, with a distance of $9.4 \mathrm{~m}$ from the center in the direction to every corner. Analysis of the phosphate content in the context of test sites was carried out in the combined samples obtained by mixing the soil of five point samples. The position of the centers of the sites was recorded based on GPS coordinates. The content of available phosphorus in the soil layer $0 \ldots 20 \mathrm{~cm}$ was determined according to Machigin, and the productivity in the field experiment was determined by the direct combining. The obtained data were interpreted using the methods of descriptive statistics, variogram and regression analysis.

\section{Results and discussion}

To calculate the optimal dose of phosphorus fertilizer for winter wheat, the level of available phosphate content in the arable soil layer is of particular importance. In this regard, additional attention requires discussion of the degree and nature of its spatial variability (Table. 1$)$.

In general, the soil of the surveyed area is characterized by a low content of available phosphates. However, due to their strong variation, the supply of wheat crops with phosphorus nutrition within the studied sample varies between acute deficiency and complete sufficiency. The high kurtosis and skewness of the empirical frequency distribution determine the features of its distribution shown in the box diagram (Figure 1). 
Table 1. Summary Statistics for the content of available phosphates in the arable layer of the southern chernozem area of $10.2 \mathrm{ha}, \mathrm{mg} / \mathrm{kg}$ of soil.

\begin{tabular}{|c|c|}
\hline Indicator & Value \\
\hline Count & 254 \\
\hline Average & 10.3268 \\
\hline Standard deviation & 5.94835 \\
\hline Coeff. of variation & $57.6013 \%$ \\
\hline Minimum & 4.0 \\
\hline Maximum & 44.0 \\
\hline Stnd. skewness & 14.391 \\
\hline Stnd. kurtosis & 23.1205 \\
\hline
\end{tabular}

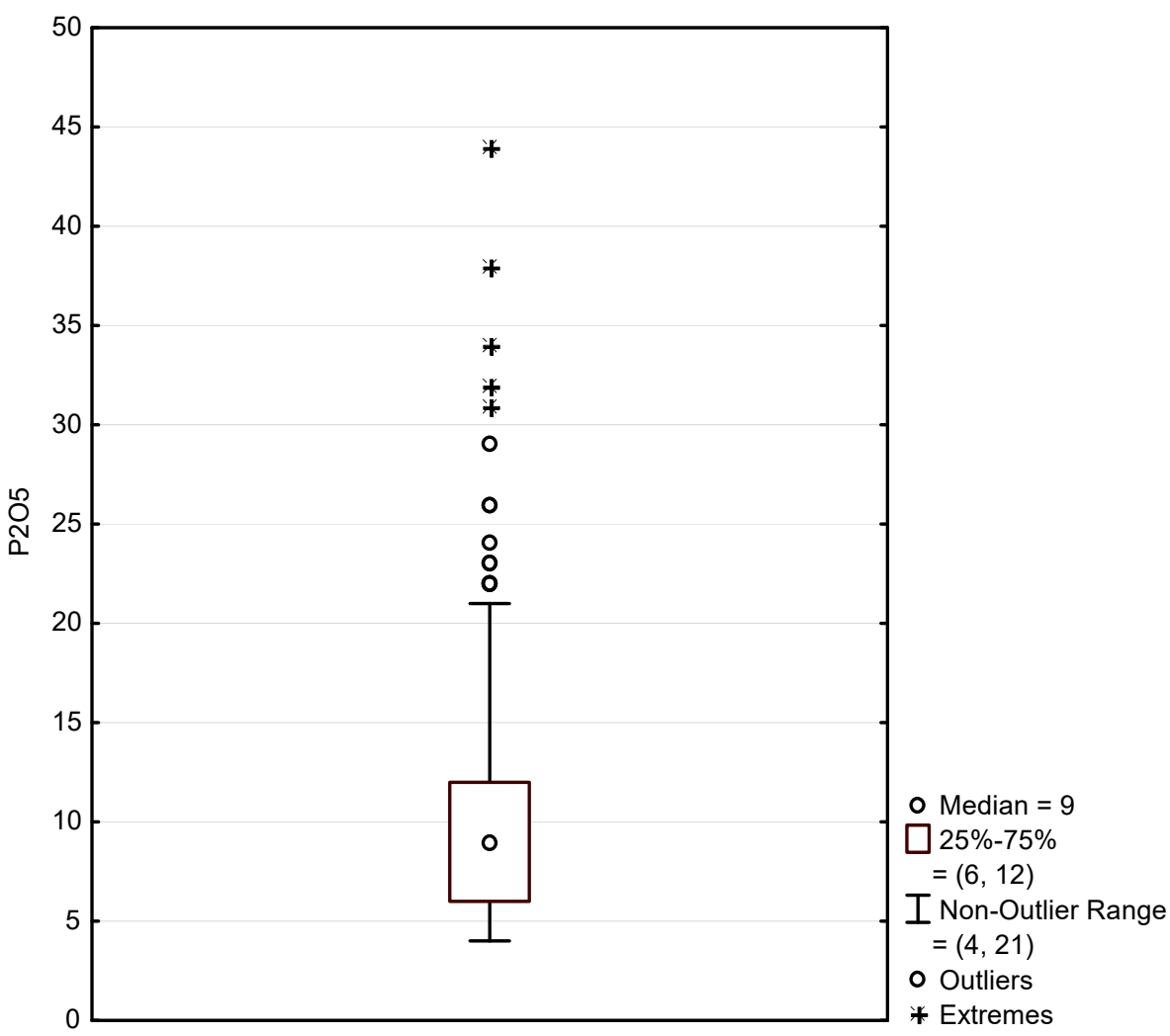

Fig. 1. The distribution of the available phosphates' content in the arable layer $(0 \ldots 20 \mathrm{~cm})$ of the southern chernozem, $\mathrm{mg} \mathrm{P}_{2} \mathrm{O}_{5}$ per $1 \mathrm{~kg}$ of soil.

The core of the distribution of the available phosphates' content (half of the studied data series) is concentrated in the relatively narrow range of values equal to $6 \mathrm{mg} / \mathrm{kg}$ of soil. This is 6.7 times less than the difference in its utmost values in the studied sample. The fundamental differences between the observed $\mathrm{P}_{2} \mathrm{O}_{5}$ variation in the soil and the normal frequency distribution are the mismatch of the average value of the variational series and its median, which is almost $13 \%$ lower, the presence of the short whisker for low values and the 4.5 times longer whisker in the region of a relatively high phosphorus content. The skewness of the distribution emphasizes the presence of outliers and marginal extreme points in this region. 
Consequently, the probability density of the data on the available phosphates' content in the soil is fundamentally different from the normal distribution. Rarely encountered abnormally high values have a disproportionately large effect on the arithmetic mean for the sample, shifting it towards the overestimation of the result. This can lead to errors in the estimated doses of phosphate fertilizers, based on the generalized values of the availability of available phosphates in the soil. In connection with the foregoing, as a generalized characteristic of these data, it will be more justified to use not the arithmetic mean, but the geometric mean $(9.1 \mathrm{mg} / \mathrm{kg})$ or median, which in our case are almost equal.

The spatial variation of the $\mathrm{P}_{2} \mathrm{O}_{5}$ content of available phosphates in the soil is characterized by an experimental semi-variogram (Figure 2).

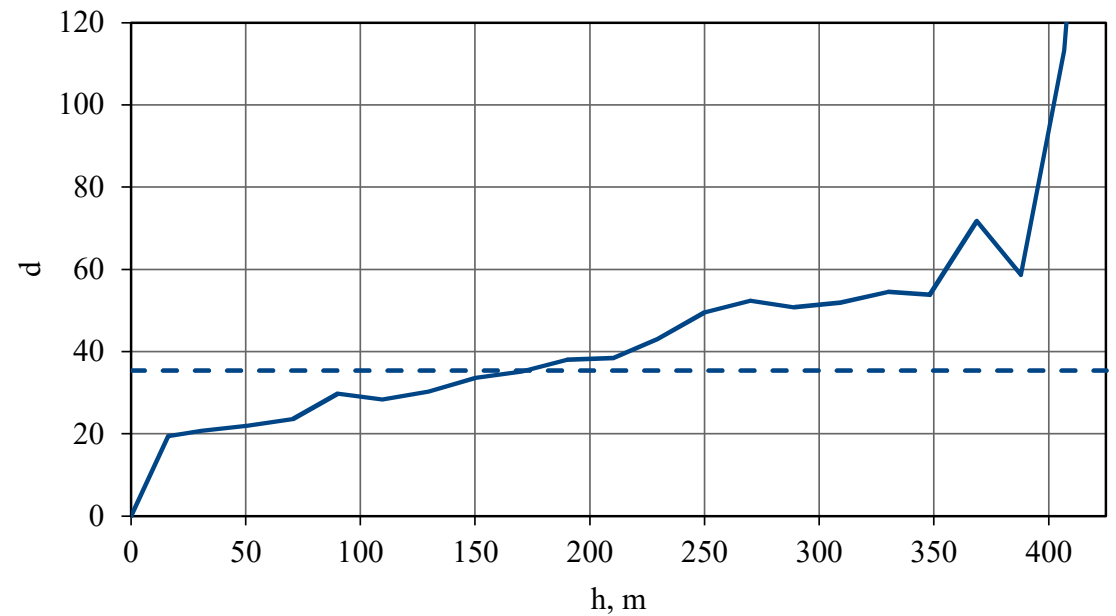

Fig. 2. Experimental semi-variogram of the available phosphates' content in the arable soil layer (according to 254 samples).

It has several inflection points: the first in the area of distances up to $20 \mathrm{~m}$, the second at a distance of 210 to $230 \mathrm{~m}$, and the third - from 350 to $370 \mathrm{~m}$ and above. Between these points, the semi-variogram is not stationary, gradually increasing by 2.0 and 1.9 times, with the suppression of the level of dispersion of the $\mathrm{P}_{2} \mathrm{O}_{5}$ content (dash line on the graph) at a distance of about $175 \mathrm{~m}$. Almost continuous growth of the variogram in the entire range of distances available for analysis (h) corresponds to an irregular, spatially continuous variability of the content of $\mathrm{P}_{2} \mathrm{O}_{5}$ in the soil. An intermediate inflection point may indicate the presence of relatively large-scale anomalies, and the extreme inflection point is a sign of the expressed global trend of this indicator. In general, the degree of contrasts in the content of available phosphates in the soil within a relatively small area and their spatial relationship actualize the use of differentiated doses of phosphorus fertilizers as part of a precise technology for growing winter wheat.

From this point of view, for a reasonable and possibly complete assessment of the availability of natural phosphorus nutrition for winter wheat crops, it is necessary but insufficient to know the amount of available phosphates in the arable layer of the soil. Along with obtaining information on the available phosphates' $\mathrm{P}_{2} \mathrm{O}_{5}$ content, the strength and nature of the action of this soil fertility indicator on grain productivity should be established. Based on the generalized data of field experiments, we obtained a regression equation describing the particular dependence of the yield of winter wheat on the available phosphates' content in the soil without the application of phosphorus fertilizers (1).

$$
Y=-36.9+32.52 P_{S}^{0.5}-4.80 P_{S}+0.244 P_{S}{ }^{1.5}
$$


where $\mathrm{Y}$ is the grain yield of winter wheat, c/ha;

$\mathrm{P}_{\mathrm{S}}$ content of available phosphates in the soil layer $(0 \ldots 20 \mathrm{~cm}), \mathrm{mg}_{2} \mathrm{O}_{5}$ per $1 \mathrm{~kg}$.

The parameters of the equation and the model as a whole are reliable at a $1 \%$ significance level. The responses of the yield of winter wheat to the increasing supply of soil with available phosphates obey the laws of slow growth and in the interval of the experimental area are represented by the ascending branch of the "softened" parabola (Figure 3).

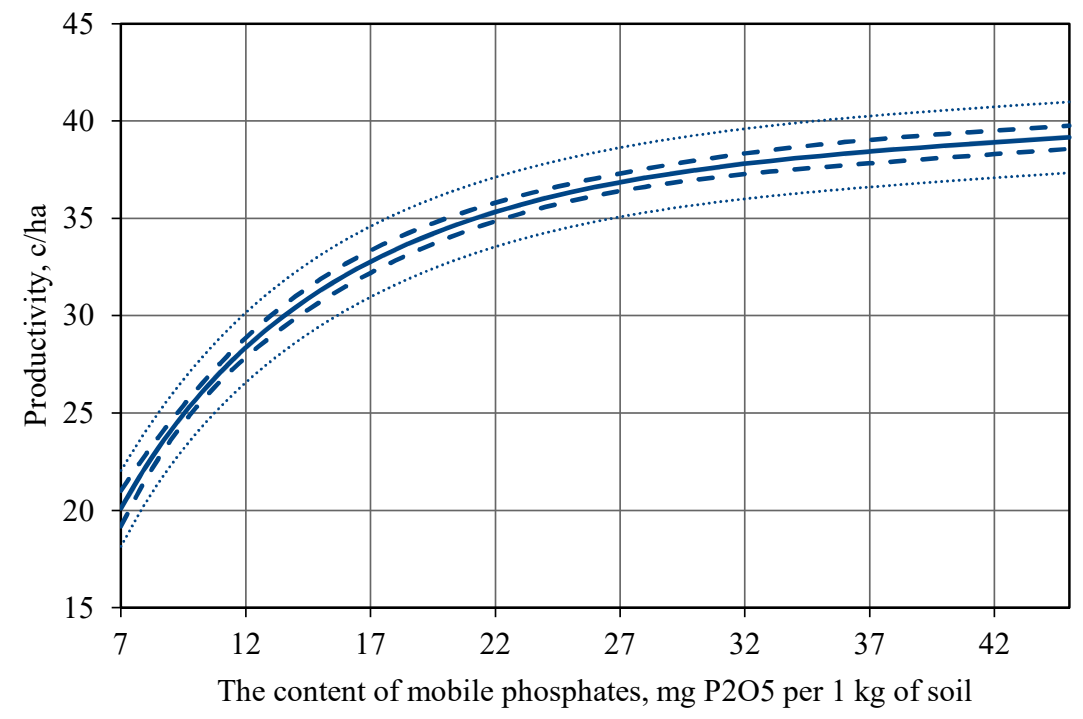

Fig. 3. Winter wheat yield depending on the content of available phosphates in the soil.

The solid curve in the diagram shows the theoretical yield responses to the content of available phosphates in the soil, the dash lines above and below this curve restrict the $95 \%$ confidence limits of the responses based on average values and individual observations: bold and thin dash lines, respectively.

In the considered interval of supplying the soil with available phosphates, the maximum yield of winter wheat is concentrated in the region of high $\mathrm{P}_{2} \mathrm{O}_{5}$ contents: from $34 \mathrm{mg}$ per $1 \mathrm{~kg}$ of soil and higher. Essentially, this is the boundary dividing the region of the experiment on this factor into the limiting and stationary regions.

Based on the data obtained, it is possible to make a reasonable assumption that when the content of available phosphorus was from 34 to $45 \mathrm{mg} / \mathrm{kg}$ of soil, winter wheat crops were completely provided with this nutrient, since the yield responses to changes in its amount in the soil in this interval did not exceed the resolution limits of experiment. With a decrease in the quantity of available phosphates from $34 \mathrm{mg} / \mathrm{kg}$ and below, a statistically proven decrease in grain yield is observed, which at first looks relatively slow, then its rate is accelerating more and more. So, with the available phosphorus content of $30 \mathrm{mg} / \mathrm{kg}$ of soil, the depression of winter wheat productivity is relatively small and makes up only $4 \%$ of its maximum value. Whereas with $\mathrm{P}_{2} \mathrm{O}_{5}$ content of $20 \mathrm{mg} / \mathrm{kg}$ in the soil, yield losses already triple and reach $12 \%$, while at $10 \mathrm{mg} / \mathrm{kg}$ they exceed $34 \%$. With a minimum amount of available phosphorus in the soil $-7 \mathrm{mg} / \mathrm{kg}$, the yield of winter wheat is only half of what is possible under these conditions with sufficient supply of phosphorus nutrition.

Based on the calculation of spatially differentiated doses of phosphorus fertilizer for winter wheat grown according to the precise technology, along with data on the local availability of phosphates in the soil and yield responses to it, it is necessary to use a 
quantitative description of the dependence of crop productivity on phosphorus fertilizer application rates.

Based on the regression modeling of the effect on the yield of winter wheat of increasing doses of phosphorus at a low availability of phosphates in the soil $(10 \mathrm{mg} / \mathrm{kg})$ according to our field experiments, we obtained the equation of the desired dependence (2).

$$
Y=25,4+0,404 P-0,026 P^{1,5}
$$

where $\mathrm{Y}$ is the grain yield of winter wheat, $\mathrm{c} / \mathrm{ha}$;

$\mathrm{P}$ dose of phosphate fertilizer, $\mathrm{kg} \mathrm{P}_{2} \mathrm{O}_{5}$ per 1 ha.

The parameters of the equation and the model as a whole are reliable at a $1 \%$ significance level.

The response of winter wheat yields to increasing doses of phosphorus fertilizer has a expressed curvature and generally obeys the law of slow growth, and the experimental area covers both the limiting and stationary regions (Figure 4).

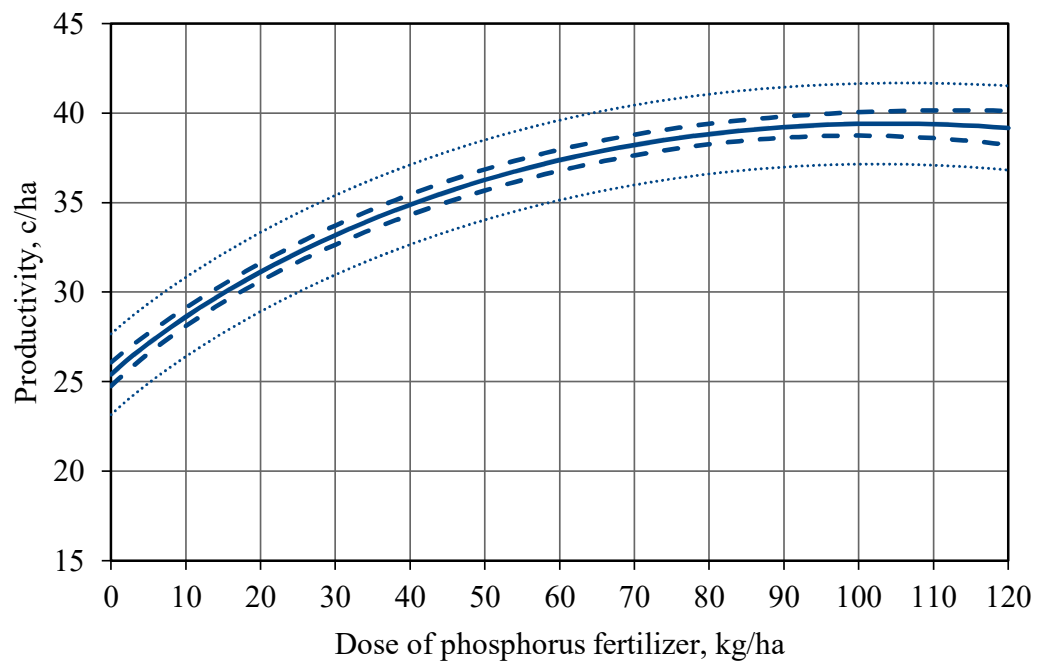

Fig. 4. Winter wheat yield depending on the dose of phosphorus fertilizer.

The designations of the curves of the diagram under discussion are analogous to those in the previously considered graph (Figure 3). Under the conditions of the experiment, the maximum yield, taking into account the resolution of the regression, was obtained with at least $70 \mathrm{~kg} / \mathrm{ha}$ a.s. of phosphorous fertilizers. A further increase in the dose of phosphorus did not lead to any significant and statistically provable change in grain yield.

As follows from the graph associated with the analyzed chart (Figure 4), the use of phosphorus fertilizers at this dose fully compensated the deficiency in the availability of available phosphates in the soil.

Reducing the dose of phosphorus fertilizers below $70 \mathrm{~kg} / \mathrm{ha}$ a.s. led to a progressive decline in winter wheat productivity. So, when applying $50 \mathrm{~kg} / \mathrm{ha}$ a.s. of phosphorous fertilizers it decreased by $8 \%$ compared with the maximum, with the application of only 30 $\mathrm{kg} / \mathrm{ha}$ a.s. of phosphates yield losses were almost doubled and consisted of almost $16 \%$, and in the variant without application of phosphorus reached $36 \%$. Studies have shown that the surveyed area of southern micellar-carbonate low humus chernozem is characterized by a generally low content of available phosphates. The strong variation and spatial distribution of this indicator of soil fertility caused the formation of small-contour plots with significant contrasts in the availability of phosphorus nutrition for winter wheat: from an expressed 
deficiency to complete sufficiency. A quantitative assessment of the influence of local conditions of available phosphates' content in the soil on the yield of winter wheat allows the corresponding nonlinear dependence found in the field experiment. In such soil conditions, phosphorus fertilizers can be effectively used in the spatial differentiation of the doses of their application. Their optimization is possible on the basis of the quantitative dependence of winter wheat productivity on increasing doses of phosphorus application found in the experiment.

\section{Conclusions}

The surveyed soil is characterized by small contour areas with significant contrasts in the content of available phosphates in the layer $(0 \ldots 20 \mathrm{~cm})$ : from 2 to 5 times.

In order to get the maximum yield of winter wheat, the content of available phosphates in the $20 \mathrm{~cm}$ layer should not be lower than $34 \mathrm{mg}$ of $\mathrm{P}_{2} \mathrm{O}_{5}$ per $1 \mathrm{~kg}$ of soil, the yield at the level of $95 \%$ of the maximum provides a $\mathrm{P}_{2} \mathrm{O}_{5}$ content of $29 \mathrm{mg} / \mathrm{kg}, 90 \%-22,80 \%-15$, $70 \%-11$ and $50 \%-7 \mathrm{mg} / \mathrm{kg}$.

To fully compensate the deficiency of phosphorus nutrition with a soil content of 10 $\mathrm{mg} / \mathrm{kg}$ of available phosphates' $\mathrm{P}_{2} \mathrm{O}_{5}$, it is necessary to apply for winter wheat $70 \mathrm{~kg} / \mathrm{ha}$ of phosphorus fertilizer, to compensate for $90 \%, 45 \mathrm{~kg} / \mathrm{ha}$ and $80 \%-20 \mathrm{~kg} / \mathrm{ha}$ a.s. of phosphorous fertilizers.

An important condition for ensuring the effectiveness of the winter wheat growing technology, taking into account the soil characteristics considered, may be the use of spatially differentiated doses of phosphate fertilizers.

\section{References}

1. J. Shen, Z. Cui, Y. Miao, G. Mi, F. Zhang, Global Food Security 2(1), 1-8 (2013)

2. A. Khan, G. Lu, M. Ayaz, H. Zhang, S. Zhang, Agric. Ecosyst. Environ. 25615, 1-11 (2018)

3. R. Wang, Z. Yao, Y. Lei, Agric. Ecosyst. Environ. 2691, 22-29 (2019)

4. Xin-kai Zhu, Chun-yan Li, Zong-qing Jiang, Lian-lian Huang, Yong-xin Peng, Journ. Integrat. Agric. 11(7), 1103-1110 (2012)

5. Lin-lin Shi, Ming-xing Shen, Chang-yin Lu, Hai-hou Wang, Tong-dong Wu, Journ. Integrat. Agric. 14(12), 2446-2455 (2015)

6. Li-yun Kang, Shan-chao Yue, Shi-qing Li, Journ. Integrat. Agric. 13(9), 2028-2039 (2014)

7. R.P. Lollato, B.M. Figueiredo, J.S. Dhillon, D.B. Arnall, W.R. Raun, Field Crops Research 23615, 42-57 (2019)

8. M. Hejcman, E. Kunzová, P. Šrek, Field Crops Res. 139, 30-38 (2012)

9. Yu Wang, Shu-yun Chi, Tang-yuan Ning, Shen-zhong Tian, Zeng-jia Li, Journ. Integrat. Agric. 12(2), 263-272 (2013)

10. H. Chen, A. Deng, W. Zhang, W. Li, F. Chen, Crop Journ. 6(6), 589-599 (2018)

11. Bin Xi, Li-mei Zhai, Jian Liu, Shen Liu, Hong-bin Liu, Journ. Integrat. Agric. 15(1), 200-208 (2016)

12. Xiuli Xin, Shengwu Qin, Jiabao Zhang, Anning Zhu, Xianfeng Zhang, Field Crops Res. 208, 27-33 (2017)

13. Kai-lou Liu, Tian-fu Han, Jing Huang, Shui-qing Zhang, Hui-min Zhang, Journ. 
Integrat. Agric. 19(3), 848-858 (2020)

14. Ming-gang Xu, Hua-jun Tang, Xue-yun Yang, Shi-wei Zhou, Journ. Integrat. Agric. 14(12), 2401-2404 (2015)

15. Wei-wei Zhang, Xiao-ying Zhan, Shu-xiang Zhang, Khalid Hamdan Mohamed Ibrahima, Ming-gang Xu, Journ. Integrat. Agric. 18(3), 667-676 (2019) 